\title{
CILOSTAZOL ATTENUATES DIABETIC NEPHROPATHY IN RATS VIA ELEVATION OF PLASMA SOLUBLE RECEPTOR FOR ADVANCED GLYCATION END-PRODUCTS
}

\author{
Soad L. Kabil \\ Department of Clinical Pharmacology, Faculty of Human Medicine, Zagazig \\ University, Egypt
}

Corresponding author: E-mail: soadkabil2004@gmail.com

\begin{abstract}
Cilostazol is a phosphodiesterase III inhibitor with antiplatelet and vasodilating properties. Cilostazol effectively attenuated severity of diabetic angiopathy. However, the underlying mechanisms involved in its beneficial effect against diabetic nephropathy are not fully elucidated. Type- 1 diabetic rats received cilostazol $(25 \mathrm{mg} / \mathrm{kg} / \mathrm{day}$, oral for 12 weeks). Fasting blood glucose, serum lipids, renal nuclear factor $\kappa \mathrm{B}(\mathrm{NF}-\kappa \mathrm{B})$ and interluckin-6 (IL-6), kidney function markers, oxidative stress parameters were examined. The plasma soluble receptor for advanced glycation end products (sRAGE) was assayed. Renal advanced glycation end products (AGEs) level was assayed. Renal histopathological study was also performed. The results showed improvement in kidney structure and function post cilostazol treatment. Furthermore, cilostazol elevated the circulating plasma sRAGE level and decreased renal AGEs, NF- $\kappa$ B and IL-6 levels. Moreover, the renal levels of reduced glutathion, superoxide dismutase and heme oxygenase-1 increased associated with reduction in malondialdehyde suggesting enriched antioxidant status in the kidney. Conclusion, Cilostazol ameliorates diabetic renal injury which may be, in part, due to elevation of circulating plasma sRAGE, lowering of renal AGEs level and in other part the anti-inflammatory action and enhancement of the renal antioxidant status.
\end{abstract}

Keywords: Cilostazol, diabetic nephropathy, streptozotocin, soluble receptor of advanced glycation end products 


\section{INTRODUCTION}

Diabetic nephropathy is a serious insult of prolonged uncontrolled hyperglycemia. It represents the principle reason for end stage renal failure worldwide. Large percentage of diabetic patients develops structural and functional renal alterations which require dialysis or transplantation (Mestry et al. 2017). Long standing hyperglycemia induces Maillard reaction "non-enzymatic reaction of reduced sugars with amino groups of proteins and lipids" with production of early glycation products named amadori products that further produce irreversibly cross linked derivatives known as advanced glycation end products (AGEs) (Singh et al. 2001).

Involvement of AGEs in the development of diabetic angiopathy is strongly evident (Fracasso et al. 2019). AGEs via interacting with their specific receptors [receptor for AGEs (RAGE)] initiate a plethora of intracellular and extracellular detrimental effects. AGEs/RAGE interaction recruits downstream cascades as oxidative stress, autophagy, pro-inflammatory transcription factors as nuclear factor $-\kappa B(N F-\kappa B)$, cytokines (interleukins and tumor necrosis factor- $\alpha$ ), Intercellular Adhesion Molecule-1 (ICAM-1) and Vascular Cell Adhesion Molecule-1 (VCAM-1) with subsequent vascular remodeling and long lasting vascular injury which trigger atherosclerosis and endothelial damage in diabetic microvascular insult ( $\mathrm{Xu}$ et al. 2016). Also, RAGE activation contributes to vasoconstriction via enhancing endothelin-1 expression and interfering with nitric oxide biosynthesis (Quade-Lyssy et al. 2013).

AGEs induce glomerulosclerosis, increased vascular permeability to albumin, and thickened glomerular basement membrane with mesangial expansion which represent the main features of diabetic nephropathy. Additionally, AGEs induce apoptotic mesangial cell death and dysfunction causing early renal dysfunction (Lee et al. 2015). Diabetic patients have a metabolic memory which explains why the diabetic vascular complications continue to occur despite efficient glycemic control. AGEs were claimed to be involved in development of the metabolic memory and hence effective contributors to diabetic nephropathy (D'Agati and Schmidt 2010). Diabetic homozygous RAGE revoked mice did not develop pathologic features of nephropathy (Brosius et al. 2010). Therapies that interfere with AGEs/ RAGE signaling proved effective in attenuating diabetic nephropathy in experimental studies (Sanajou et al. 2019). Full-length RAGE binds AGEs and induces the adverse signaling cascades. sRAGE originates from proteolysis cleavage from RAGE (Lu et al. 2011). sRAGE does not possess transmembrane and cytoplasmic domains making it unable to trigger the adverse signaling events. sRAGE is the predominant sort in serum and acts as a decoy receptor that prevent the interaction of ligands as AGEs with full length RAGE. Therefore, sRAGE gives a natural defense by intercepting the interaction of AGEs with full-length RAGE and prevents the activation of adverse signaling events triggered by the AGE-RAGE axis (Dozio et al. 2019).

Cilostazol is a phosphodiesterase III inhibitor, widely prescribed in clinical settings (i.e. peripheral artery disease) for its antiplatelet and vasodilating properties (Takeshita et al. 2014). Since cilostazol has anti-inflammatory, antioxidant and antifibrotic effects (Su et al. 2019) therefore, it is interesting to study its role in diabetic nephropathy as a protective tool in addition to clarify the underlying possible 
mechanisms involved in its effect to alleviate diabetic renal damage. So, this study hypothesized that the protective effect of cilostazol on diabetic nephropathy may be mediated, in part, through enhancing the circulating plasma sRAGE level and reducing renal AGEs level.

\section{Materials and Methods}

\section{Chemicals}

Cilostazol (Otsuka Pharmaceutical Co. Ltd. Tokyo, Japan), Streptozotocin (STZ) and dimethyl sulphoxide (DMSO, 0.1\%- vehicle of cilostazol) (Sigma-Aldrich, St. Louis-Mo., USA).

\section{Animals}

Male Wistar rats weighing180-220 gm, 9 weeks old were obtained from the Animal Breeding and Research Center, Faculty of Veterinary Medicine, Zagazig University, Egypt. The room was maintained under stable temperature $\left(21 \pm 2{ }^{\circ} \mathrm{C}\right)$, humidity ranged from 50\%-60\% and 12-h light/dark cycle. Rats received a standard pellet diet with free access to water. The rats were acclimatized for 6 days before the study. The protocol was approved by the Institutional Research Board, Zagazig University (2019/IRB/235) and in line with principles of care and use of laboratory animals of National Institutes of Health (NIH Publications No. 8023, revised 1996).

\section{Induction of type-1 diabetes mellitus in rats}

Type -1 diabetes mellitus was induced in overnight fasted rats by a single intraperitoneal injection (i.p.) of STZ in a dose of $65 \mathrm{mg} / \mathrm{kg}$ of body weight freshly prepared in $0.1 \mathrm{M}$ of citrate buffer, $\mathrm{pH} 4.5$. Six days after STZ injection, diabetes was confirmed by measuring fasting blood glucose level in blood samples obtained from rat tail vein (One Touch SureStep Meter, LifeScan, Calif, USA). The selected rats had blood glucose level above $270 \mathrm{mg} / \mathrm{dl}$ (Sanajou et al. 2019).

\section{Experimental design}

Twenty four rats were randomly allocated into 2 groups $(n=12)$. Control group received a single i.p. of $0.1 \mathrm{ml}$ of citrate buffer (vehicle) and diabetic group where type 1 diabetes mellitus was induced. The control group was further subdivided into 2 subgroups $(\mathrm{n}=6)$. Control group received DMSO $(0.1 \%) 1 \mathrm{ml} / \mathrm{kg} / \mathrm{day}$ orally and cilostazol control (Cilo control) group received cilostazol orally, $25 \mathrm{mg} / \mathrm{kg} / \mathrm{day}$ (Lee et al. 2010). Diabetic rats were further subdivided into 2 subgroups $(n=6)$ : diabetic (DM) group received DMSO $(0.1 \%) 1 \mathrm{~mL} / \mathrm{kg} / \mathrm{day}$ orally; cilostazol treated diabetic (Cilo/DM) group rats received cilostazol, $25 \mathrm{mg} / \mathrm{kg} /$ day orally for 12 weeks started once diabetes mellitus was confirmed.

The body weight and blood glucose level were checked weekly till end of the study. Diabetic rats were injected daily with two units of Ultralente insulin (Ultratard HM; Novo Nordisc Industries, Denmark). Finally, rats were euthanized (ketamine 50 
$\mathrm{mg} / \mathrm{kg}$ i.p, midazolam $1 \mathrm{mg} / \mathrm{kg}$ i.p.) (Sanajou et al. 2019) blood and kidney samples were collected for laboratory investigations.

Urine collection, blood and tissue sampling and preparation

At the last day of study, each rat was placed in a metabolic cage to collect $24 \mathrm{~h}$ urine. Blood samples were obtained from the retro-bulbar plexus, centrifuged at $1000 \mathrm{~g}$ for $20 \mathrm{~min}$ for serum separation and stored at $-20^{\circ} \mathrm{C}$ until bioassay. Immediately after scarification, the right kidneys were excised, washed with isotonic saline and weighted to define kidney/body weight ratio. Each kidney was divided into 2 halves: one half was fixed in formaldehyde (10\%) for histological analysis. The other half was homogenized with $10 \%(\mathrm{w} / \mathrm{v})$ phosphate-buffer $(0.1 \mathrm{M}, \mathrm{pH} 7.4)$, centrifuged at $10.000 \mathrm{~g}$ for $10 \mathrm{~min}$ to obtain supernatants stored at $-80^{\circ} \mathrm{C}$ for biochemical analysis (Thallas-Bonke et al. 2008).

Assay of plasma albumin, creatinine, blood urea nitrogen (BUN), lipids, glucose and urine albumin level

These parameters were assayed quantitavely by using ELISA according to the manufacturer guidelines.

Renal assay of Kidney injury molecule-1 (Kim-1), heme oxygenase-1 (HO-1), malondialdehyde (MDA), reduced glutathione (GSH) and superoxide dismutase (SOD) activity, nuclear factor kappa B (NF-кB), interleukin-6 (IL-6) and serum transforming growth factor-B1 (TGF-B1) levels

These parameters were determined in renal tissue homogenate by ELISA according to the manufacturer instructions (Zhang et al. 2017; Sanajou et al. 2019)

\section{Plasma sRAGE measurement}

Rat sRAGE ELISA kit (cat No. SK00112-03, Adipobiotech Company, Beijing, China) was used to determine the plasma sRAGE level by quantitatively competitive enzyme immunoassay technique (Lu et al. 2011)

\section{Renal AGEs level measured by High Performance Liquid Chromatography (HPLC)}

Pentosidine level was measured in renal cortical homogenates by a reverse phase High Performance Liquid Chromatography (HPLC) as described by Requena et al. (2000).

\section{Western blot analysis of renal ICAM-1 and VCAM-1 expression}

The bicinchoninic acid protein assay kit (Sigma-Aldrich, St. Louis, MO, USA) was used (Ni et al. 2015). 


\section{Histopathological examination}

Renal tissues were fixed in formaldehyde (4\%) then embedded in paraffin. Coronal sections $(4 \mu \mathrm{m}$ thick) were stained with hematoxyline and eosin (H\&E) and periodic acid Schiff (PAS) then examined under light microscope in a blind manner by an expert pathologist in order to identify diabetic renal pathological changes such as glomerular expansion and hydropic changes (Lee et al. 2010).

\section{Statistical analysis}

The results in different groups were compared by the use of one-way analysis of variance (ANOVA) followed by Bonferroni correction. The data were expressed as mean \pm SEM. The significance was considered when $p<0.05$. The statistical analysis was performed based on SPSS Statistics for Windows, Version 16.0 (SPSS, Chicago, IL, USA).

\section{Results}

Effect of cilostazol on the body weight, kidney weight and kidney weight/body weight $\%$ in diabetic rats

Diabetic rats showed significant $(\mathrm{p}<0.05)$ weight loss in comparison with the control rats. The body weight of diabetic rats treated with cilostazol at the dose of $25 \mathrm{mg} / \mathrm{kg}$ was significantly $(\mathrm{p}<0.05)$ increased compared with the diabetic group (table 1).

The kidney weight and kidney hypertrophy index (kidney weight/body weight $\%)$ of diabetic rats were significantly $(\mathrm{p}<0.05)$ increased in relation to the control group. Diabetic rats treated with cilostazol showed significant $(\mathrm{p}<0.05)$ reduction in kidney weight and kidney hypertrophy index when compared with the diabetic group (table 1).

\section{Effect of cilostazol on plasma lipids in diabetic rats}

Diabetes caused significant $(\mathrm{p}<0.05)$ elevation in plasma LDL, TG and TC levels and decrease in HDL level. Cilostazol treatment significantly $(p<0.05)$ counteracted the above mentioned parameters in diabetic rats (table 1).

Table 1: Effect of cilostazol $(25 \mathrm{mg} / \mathrm{kg})$ on body weight, kidney weight and kidney weight/body weight $\%$ and plasma lipids level in diabetic rats

\begin{tabular}{|c|c|c|c|c|c|c|c|c|}
\hline \multirow[b]{2}{*}{ Groups } & \multicolumn{2}{|l|}{ BW (gm.) } & \multirow[t]{2}{*}{ KW (gm.) } & \multirow[t]{2}{*}{ KW/BW\% } & \multirow{2}{*}{$\begin{array}{l}\text { LDL } \\
(\mathrm{mmol} / \mathrm{L})\end{array}$} & \multirow{2}{*}{$\begin{array}{l}\text { HDL } \\
(\mathrm{mmol} / \mathrm{L})\end{array}$} & \multirow{2}{*}{$\begin{array}{l}\text { TG } \\
(\mathrm{mmol} / \mathrm{L})\end{array}$} & \multirow{2}{*}{$\begin{array}{c}\mathrm{TC} \\
(\mathrm{mmol} / \mathrm{L})\end{array}$} \\
\hline & $\begin{array}{l}\text { Initial } \\
\text { (established } \\
\text { DM) }\end{array}$ & $\begin{array}{l}\text { Final ( the last } \\
\text { day of the } \\
\text { study) }\end{array}$ & & & & & & \\
\hline control & $192.15 \pm 6.5$ & $300.7 \pm 8.9$ & $1.41 \pm 0.5$ & $0.31 \pm 0.1$ & $0.53 \pm 0.2$ & $0.61 \pm 0.4$ & $0.29 \pm 0.5$ & $1.64 \pm 0.11$ \\
\hline $\begin{array}{l}\text { Cilo } \\
\text { control }\end{array}$ & $190.23 \pm 7.4$ & $298.4 \pm 9.3$ & $1.39 \pm 0.2$ & $0.32 \pm 0.03$ & $0.50 \pm 0.3$ & $0.62 \pm 0.2$ & $0.28 \pm 0.4$ & $1.63 \pm 0.12$ \\
\hline DM & $195.46 \pm 8.3$ & $160.3 \pm 8.4^{*}$ & $1.78 \pm 0.3^{*}$ & $0.70 \pm 0.04^{*}$ & $1.32 \pm 0.4^{*}$ & $0.41 \pm 0.3^{*}$ & $0.46 \pm 0.1^{*}$ & $2.43 \pm 0.15^{*}$ \\
\hline Cilo/DM & $188.37 \pm 9.2$ & $280.6 \pm 10.2^{\#}$ & $1.48 \pm 0.1^{\#}$ & $0.42 \pm 0.2^{\#}$ & $0.64 \pm 0.1^{\#}$ & $0.56 \pm 0.4^{\#}$ & $0.32 \pm 0.3^{\#}$ & $1.68 \pm 0.24^{\#}$ \\
\hline
\end{tabular}


Note: BW: body weight; KW: kidney weight; Cilo: cilostazol; DM: diabetes mellitus; LDL: low density lipoprotein; HDL: high density lipoprotein; TG: triglycerides; TC: total cholesterol. Data represents means \pm S.E.M, ${ }^{*} \mathrm{p}<0.05$ Vs. control group and cilo control group, ${ }^{\#}<<0.05$ Vs. DM group

\section{Effect of cilostazol on blood glucose level in diabetic rats}

Fasting blood glucose was significantly $(\mathrm{p}<0.05)$ elevated in the diabetic rats in comparison with the control rats however; this was not affected by cilostazol treatment (table 2).

\section{Effect of cilostazol on markers of kidney function in diabetic rats}

Diabetes caused significant $(\mathrm{p}<0.05)$ increase in serum creatinine and BUN levels. Treatment of diabetic rats with cilostazol significantly $(\mathrm{p}<0.05)$ lowered their levels (table 2). Serum albumin of diabetic rats was significantly decreased compared with the control rats. However, cilostazol-treated diabetic rats exhibited significant $(\mathrm{p}<0.05)$ increase in serum albumin compared with the diabetic group (table 2$)$.

The diabetic rats showed significant $(\mathrm{p}<0.05)$ increase in $24 \mathrm{~h}$ albumin level in urine when compared with control rats. Treatment of diabetic rats with cilostazol significantly $(\mathrm{p}<0.05)$ reduced urinary albumin in respect to the diabetic group (table 2$)$.

\section{Effect of cilostazol on renal Kim-1 in diabetic rats}

Diabetic rats showed significant $(\mathrm{p}<0.05)$ increase in the renal Kim-1 compared with the control group. Cilostazol treatment significantly $(\mathrm{p}<0.05)$ decreased the renal Kim-1 in respect to the diabetic untreated rats (table 2).

Table 2: Effect of cilostazol $(25 \mathrm{mg} / \mathrm{kg})$ on plasma levels of glucose, albumin, creatinine, BUN and urine albumin, renal Kim-1 in diabetic rats

\begin{tabular}{|l|l|l|l|l|l|l|}
\hline Group & Glucose & $\begin{array}{l}\text { Plasma } \\
\text { Albumin } \\
(\mathbf{m g} / \mathbf{d l})\end{array}$ & $\begin{array}{l}\text { Creatinine } \\
(\mathbf{m g} / \mathbf{d l})\end{array}$ & $\mathbf{B U N}$ & $\begin{array}{l}\text { Urine } \\
\text { albumin } \\
(\mathbf{g m} / \mathbf{2 4 h})\end{array}$ & $\begin{array}{l}\text { Kim-1 } \\
(\mathbf{n g} / \mathbf{m l})\end{array}$ \\
\hline Control & $90.25 \pm 8.2$ & $6.21 \pm 0.3$ & $0.95 \pm 0.7$ & $14.97 \pm 2.4$ & $0.07 \pm 0.01$ & $12.46 \pm 0.5$ \\
\hline $\begin{array}{l}\text { Cilo } \\
\text { control }\end{array}$ & $89.36 \pm 8.0$ & $6.11 \pm 0.01$ & $0.93 \pm 0.3$ & $14.39 \pm 2.0$ & $0.08 \pm 0.03$ & $12.20 \pm 0.6$ \\
\hline DM & $275.24 \pm 20.3^{*}$ & $2.32 \pm 0.4^{*}$ & $1.86 \pm 0.3^{*}$ & $28.63 \pm 0.4^{*}$ & $0.35 \pm 0.06^{*}$ & $48.4 \pm 8.7^{*}$ \\
\hline Cilo/DM & $270.16 \pm 24.5$ & $4.18 \pm 0.7^{\#}$ & $0.90 \pm 0.8^{\#}$ & $16.38 \pm 1.9^{\#}$ & $0.18 \pm 0.04^{\#}$ & $16.8 \pm 2.2^{\#}$ \\
\hline
\end{tabular}

Note: Cilo: cilostazol; DM: diabetes mellitus; BUN: blood urea nitrogen; Kim-1: kidney injury molecule -1 . Data represents means \pm S.E.M, ${ }^{*}$ p $<0.05$ Vs. control group and cilo control group, ${ }^{\#} \mathrm{p}<0.05$ Vs. DM group, 
Effect of cilostazol on renal oxidative stress markers and heme-oxygenase-1 (HO1) in diabetic rats

Diabetes enhanced lipid peroxidation; evidenced by significant $(\mathrm{p}<0.05)$ increase in renal malondialdehyde (MDA). However, cilostazol significantly $(p<0.05)$ decreased renal MDA in diabetic rats. Renal superoxide dismutase (SOD) and reduced glutathione (GSH) activities were markedly down-regulated in diabetic rats but treatment with cilostazol significantly upregulated them in diabetic rats (figure 1a, b, c).

Renal HO-1 content was significantly $(\mathrm{p}<0.05)$ increased in diabetic group in respect to control group. Treatment with cilostazol to diabetic and control rats significantly $(\mathrm{p}<0.05)$ increased the renal HO-1 content (Figure 1d).
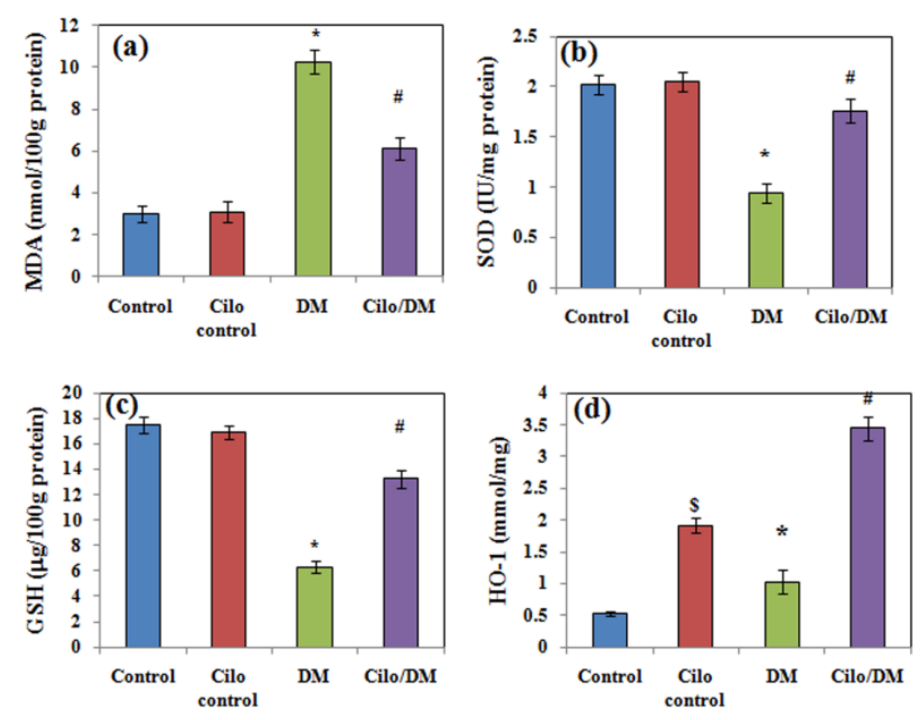

Figure 1 Effect of cilostazol (25mg/kg/day oral for 12 weeks) on renal: (a) MDA; (b) SOD; (c) GSH; (d) HO-1 levels in STZ-treated rats. Cilo: cilostazol; DM: diabetes mellitus; MDA: malondialdehyde; SOD: superoxide dismutase; GSH: reduced glutathione; HO-1: heme oxygenase-1. Data represents mean \pm SEM, ${ }^{*} p<0.05$ vs. control group and cilo control group, ${ }^{\#} \mathrm{p}<0.05$ vs. DM group.

Effect of cilostazol on renal NF-кB, IL-6 level and serum transforming growth factor $-\beta 1$ (TGF- $\beta 1$ ) in diabetic rats

Diabetes significantly $(\mathrm{p}<0.05)$ increased renal NF- $\kappa$ B, IL-6 and serum TGF- $\beta 1$ in respect to control rats. Cilostazol treatment to diabetic rats produced significant $(\mathrm{p}<0.05)$ decrease in the aforementioned parameters (figure $2 \mathrm{a}, \mathrm{b}, \mathrm{c}$ ).

\section{Effect of cilostazol on renal expression of ICAM-1 and VCAM-1}

Western blot analysis of renal ICAM-1 and VCAM-1expression levels in diabetic untreated rats revealed significant $(p<0.05)$ elevation compared with the control rats. While, treatment of diabetic rats with cilostazol produced significant $(\mathrm{p}<$ 0.05 ) reduction in renal expression of both parameters (Figure $2 \mathrm{~d}, \mathrm{e}, \mathrm{f}$ ). 

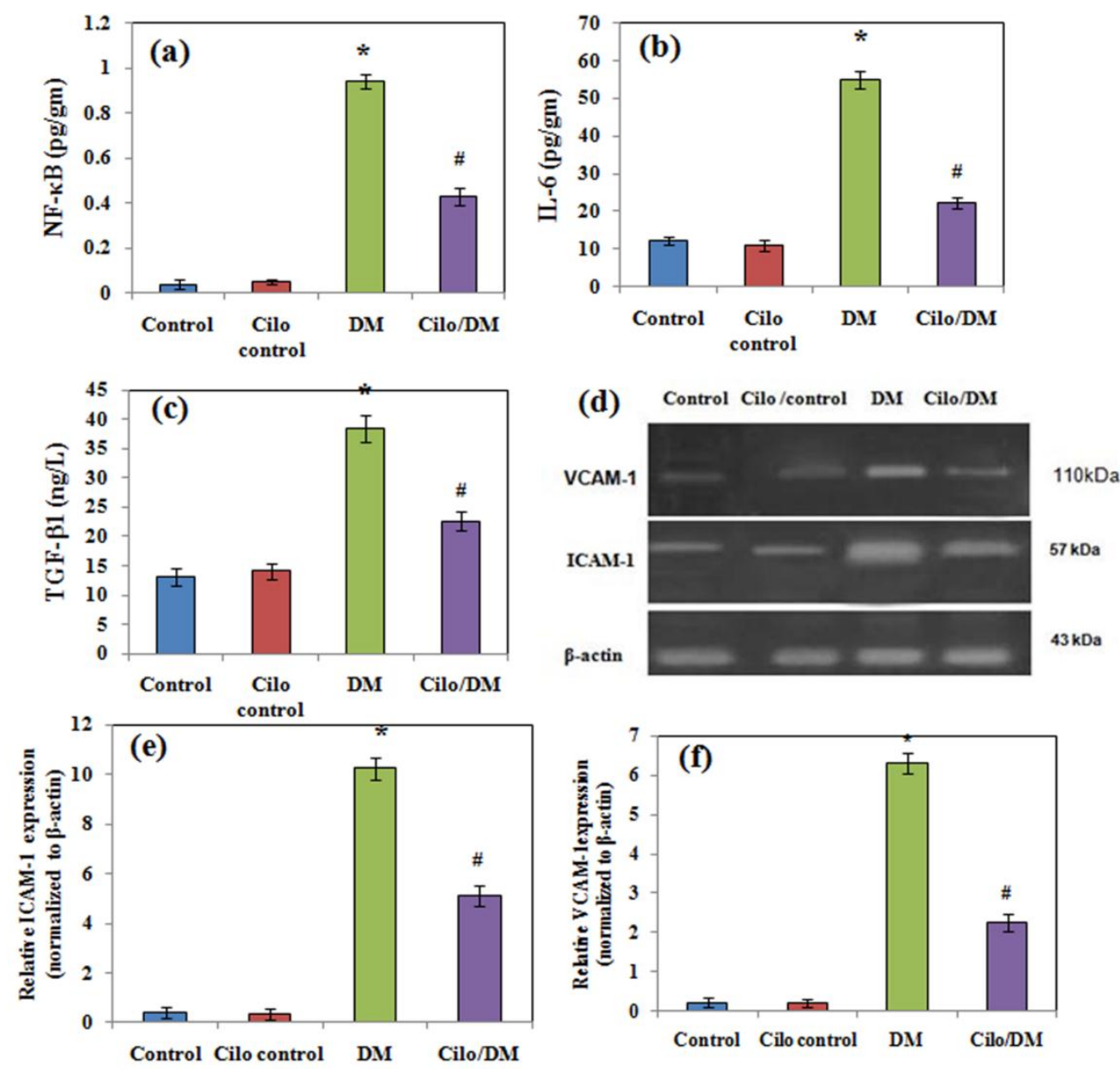

Figure 2 Effect of cilostazol (25mg/kg/day oral for 12 weeks) on renal: (a) NF- $\kappa B$; (b) IL-6 levels; (c) serum TGF- $\beta 1$ level; (d) Western Blot analysis of renal expression of ICAM-1 and VCAM-1 in STZ-treated rats; Densitometric quantification of Western blot bands of: (e) ICAM-1 and (f) VCAM-1 in relation to $\beta$-actin. Cilo: cilostazol; DM: diabetes mellitus; NF- $\kappa$ B: nuclear factor kappa B; IL-6: interleukin-1; TGF- $\beta 1$ : transforming growth factor $-\beta 1$. ICAM-1: intercellular adhesion molecule-1; VCAM-1: vascular cell adhesion molecule-1. Data represents mean \pm SEM, ${ }^{\$} \mathrm{p}<0.05$ vs control group, ${ }^{*} \mathrm{p}<0.05 \mathrm{~V}$ s control group, ${ }^{*} \mathrm{p}<0.05$ vs. DM group.

\section{Effect of cilostazol on plasma sRAGE level in diabetic rats}

Diabetes caused significant $(p<0.05)$ decrease in the serum sRAGE compared with the control rats. This reduction in the circulating sRAGE was counteracted by cilostazol treatment to diabetic rats (figure 3a).

\section{Effect of cilostazol on renal AGEs level in diabetic rats}

Renal pentosidine content was significantly $(\mathrm{p}<0.05)$ elevated in diabetic group compared with control group. In cilostazol treated diabetic rats, renal pentosidine content was significantly $(\mathrm{p}<0.05)$ lower than that in untreated diabetic rats (figure $3 b)$. 

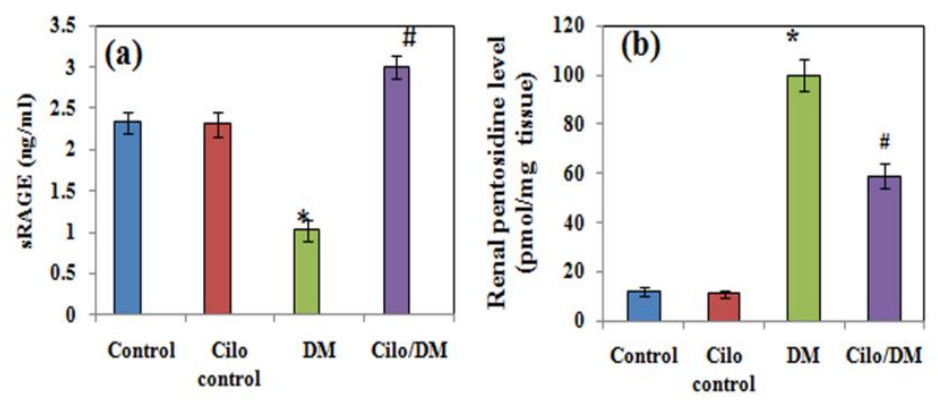

Figure 3 Effect of cilostazol (25mg/kg/day oral for 12 weeks) on: (a) plasma level of sRAGE; (b) renal pentosidine level estimated by HPLC. Cilo: cilostazol; DM: diabetes mellitus; sRAGE: soluble receptor for advanced glycation end products;. Data represents mean \pm SEM, ${ }^{*} \mathrm{p}<0.05$ vs control group and cilo control group, ${ }^{*} \mathrm{p}<0.05$ vs DM group.

\section{Effect of cilostazol on the diabetic renal histopathological changes in rats.}

Hematoxyline and eosin $(\mathrm{H} \& \mathrm{E})$ stained renal tissue specimens of the control group showed normal renal architecture, glomerular size and basement membrane width meanwhile, renal tissue specimens of diabetic rats showed moderate to severe degree of glomerular mesangial expansion, increased Bowman's space, cellular proliferation, interstitial expansion and vacuolar tubular degeneration. Cilostazol treatment to diabetic rats significantly $(\mathrm{p}<0.05)$ reduced diabetic renal pathological changes (figure $4 \mathrm{a}-\mathrm{d}$ ).

Periodic Acid Schiff (PAS) stained kidney specimens of diabetic rats exhibited high intensity of PAS positivity when compared with the negative control rats. Cilostazol treatment to diabetic rats significantly $(\mathrm{p}<0.05)$ reduced the intensity of PAS positivity (figure $4 \mathrm{e}-\mathrm{h}$ ).

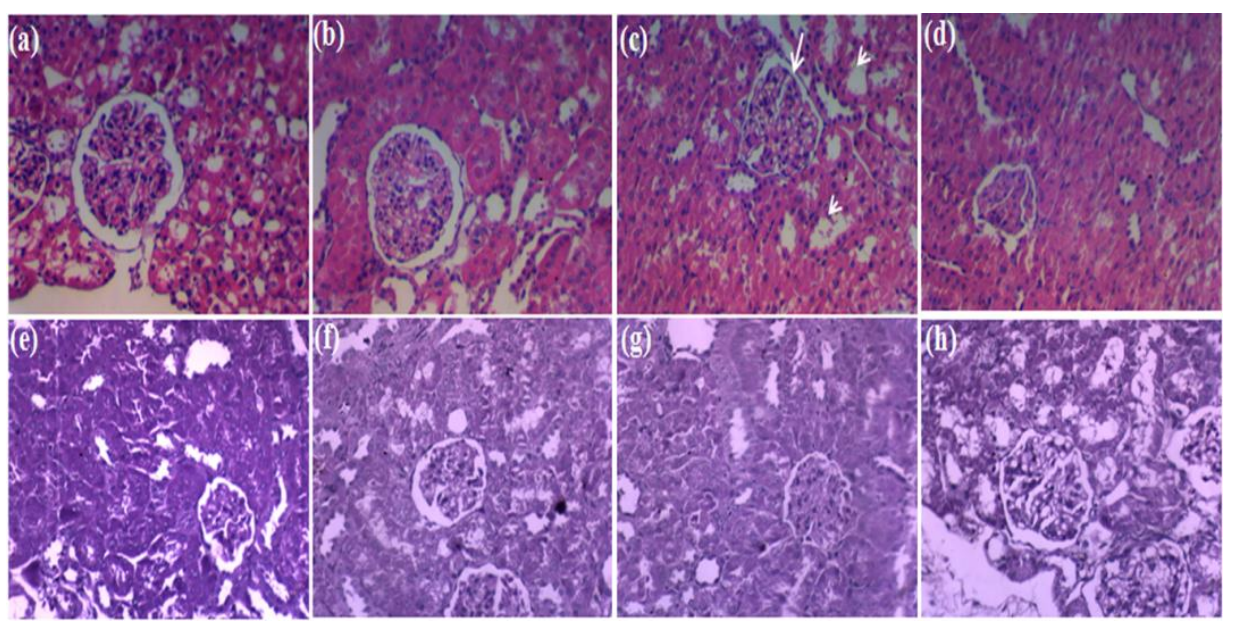

Figure 4 Photomicrographs of Hematoxylin and eosin-stained renal sections (magnification $\times 400)$. (a): Control group showed normal renal architecture. (b): Cilo/control group showed normal appearance of glomeruli and tubules. (c): DM group showed glomerular enlargement, mesangial proliferation (black arrow) with hydropic 
degeneration of renal tubules (white arrow). (d): Cilo/DM group showed glomeruli returned nearly to normal size with reduction in hydropic changes.

Photomicrographs of Periodic Acid Schiff (PAS) stained renal sections (magnification $\times 400)$. (e): Control group showed normal glomerular volume. (f): Cilo control group showed normal glomerular size and mesangial matrix (g): DM group showed high intensity of PAS stained expanded mesangial matrix area (black arrows). (h): Cilo/DM group showed marked reduction in glomerular expansion with marked reduction in the intensity of PAS staining.

\section{Discussion}

Glucose dysregulation is associated with accelerated non-enzymatic glycation of proteins and lipids with AGEs formation which play a pivotal role in pathogenesis of diabetic nephropathy (Singh et al. 2014).

In the current study, cilostazol improved the deteriorated kidney function in diabetic rats as it improved albuminuria, lowered plasma lipids, creatinine, urea and renal Kim-1. Cilostazol improved diabetic renal structural damage as evidenced histologically and kidney hypertrophy index. This coincided with that of Lee et al. 2010 who reported that cilostazol ameliorated diabetic renal morphological, functional insult and retrived serum albumin level in STZ-treated rats. Diabetic dyslipidemia is a key contributor to renal injury and albuminuria (Tani et al. 2000). In the present study, diabetic rats exhibited elevation in plasma TG, TC and LDL with decreased HDL and Cilostazol treatment counteracted these pathological changes. Cilostazol may help lessen diabetic nephropathy symptoms by tempering lipid metabolism and dyslipidemia. Tani and his colleagues (2000) reported that cilostazol decreased plasma TG and increased HDL levels via increasing lipoprotein lipase activity. The present study demonstrated an elevation in renal Kim-1 in diabetic rats which acts as a compensatory tool to enhance re-epithelization and antagonize apoptosis. Cilostazol reduced renal Kim-1 indicating modulation of kidney injury. This finding coincided with that of Zhao et al. (2011) who reported an enhanced glomerular expression of Kim-1 in diabetic glomerulopathy. Engagement of AGEs with RAGE activates downstream cascades that facilitate transcription and expression of proinflammatory cytokines like TNF- $\alpha$, IL-6, TGF- $\beta 1$ which upregulate expression of collagen, laminins and fibronictin in glomerular mesangial cells (Singh et al. 2014), adhesion molecules i.e VCAM-1, ICAM-1 with activation of NF- $\kappa \beta$ signaling pathway. Enhanced renal expression of VCAM-1 and ICAM-1 in diabetic rats leads to extracellular matrix accumulation, mesangial expansion and thickened basement membrane with microalbuminuria through macrophage adhesion and lymphocyte infiltration (Ni et al. 2015). The current study demonstrated elevation in renal VCAM-1 and ICAM-1 in diabetic rats which were attenuated with cilostazol treatment indicating that cilostazol may inhibit accumulation of extracellular matrix and renal insult in diabetic nephropathy via downregulating renal VCAM-1 and ICAM-1 expression. Wang and his colleagues (2008) reported that cilostazol modulated the renal inflammatory process in STZ treated rats through prevention of $\mathrm{NF}-\mathrm{\kappa B}$ activation in addition to decreased renal expression of proinflammatory mediators. AGEs trigger activation of TGF- $\beta 1$ and its downstream cascades in diabetic glomeruli (Fukami et al. 2004). TGF- $\beta 1$ is a fibrogenic cytokine 
and a central player in development of diabetic nephropathy (Ziyadeh 2004). The current study demonstrated that cilostazol reduced serum TGF- $\beta 1$ in diabetic rats may be via intercepting AGEs induced activation of TGF- $\beta 1$ with subsequent inhibition of fibrosis and mesangial hypertrophy. In agreement with the current result, Takeshita et al. (2014) reported that cilostazol repressed TGF- $\beta 1$ in brain ischemia reperfusion insult, preserved integrity of blood brain barrier and inhibited fibrotic changes in brain tissue. Oxidative stress elicited by AGES is a key factor in emergence of diabetic nephropathy. Oxidation together with inflammation trigger generation of HO-1 which acts as a protective mechanism against oxidative tissue damage ( $\mathrm{Lv}$ et al. 2011). The present work demonstrated that cilostazol increased renal HO-1 level which is a principle cell endeavor for renoprotection. Coinciding with our result, Park et al. (2010) found that cilostazol upregulated nuclear factor E2-related factor-2 (Nrf2) / HO-1 pathway enhancing SOD and other antioxidant enzymes generation. HO-1 eased hepatic lipid accumulation, fibrotic changes and vascular injury (Sodhi et al. 2015). The generated reactive oxygen species (ROS) modifies activation of protein kinase $-\mathrm{C}$ (PKC), numerous cytokines and transcription factors (Yamagishi et al. 2005; Feng et al. 2018).

AGEs activate NADPH oxidase, enhance neutrophil respiratory burst activity with ROS generation (Moldogazieva et al. 2019). In the current study, cilostazol enhanced the antioxidant renal system; supported by increased renal GSH, SOD and HO-1 levels. However, cilostazol attenuated the renal lipid peroxidation reaction; evidenced by reduced renal MDA levels. This coincided with that of Koike and coworkers (2007) who demonstrated that cilostazol inhibited PKC mediated oxidative stress via inhibition of phosphatidyl inositol-3 kinase (PI-3K) pathway in rat glomeruli. In glomerular mesangial cells exposed to injury by AGEs, silent information receptor regulator-1(Sirt-1) activation downregulated fibronectin and TGF- $\beta 1$ via stimulation of Keap1/NrF2/ARE pathway (Huang et al. 2017). In our previous study, cilostazol upregulated Sirt-1 in hepatocytes contributing to its beneficial role against bile duct ligation induced liver insult (Kabil 2018). AGE/RAGE interaction is largely implicated in development of diabetic nephropathy (Daffu et al. 2013). Interference of AGE binding to RAGE is considered a therapeutic target to slow down or prevent diabetic nephropathy.

sRAGE is a natural clearing system for AGEs. It binds with AGEs to prevent their interaction with RAGE facilitating their degradation (Dozio et al. 2019). The current results showed that cilostazol reduced renal pentosidine in diabetic rats. Binding of AGEs with sRAGE, which acts as a decoy, does not activate downstream cascades like with the full length RAGE (Lindsey et al. 2009; Fishman et al. 2018). Many studies identified the protective role of sRAGE in diabetic angiopathy (Bucciarelli et al. 2008; Thallas-Bonke et al. 2008). Enhancement of the plasma sRAGE level by cilostazol is associated with improvement in kidney structure and function which was affected by prolonged hyperglycemia. Liu and co-workers (2015) reported that cilostazol improved diabetic induced peripheral arterial vascular disease in diabetic patients through augmentation of plasma sRAGE level. Diabetic RAGE null mice did not develop significant renal pathological changes with reduced generation of proinflammatory mediators and ROS (Wendt et al. 2003). Cilostazol suppressed generation of proinflammatory mediators via inhibition of RAGE/ERK/NF- $\kappa \beta$ signaling pathway (Liu 
et al. 2015). The present results are in harmony with Moldogazieva and his colleagues (2019) who demonstrated that blockade of RAGE by sRAGE downregulated generation of cytokines as TNF- $\alpha$ and IL-6 as well as matrix metalloproteinase-2,-3and -9 expression in diabetic mice. Lu et al. (2011) found that atorvastatin improved renal diabetic dysfunction via elevating the circulating plasma sRAGE level and reducing the renal RAGE expression. The exact mechanism underlying the effect of cilostazol on plasma sRAGE is still unclear and needs further investigation.

In conclusion, cilostazol attenuated the diabetic renal pathological and functional damage. This effect of cilostazol probably, in part, resulted from elevating the circulating plasma sRAGE, lowering of renal AGEs level and subsequent inhibition of interaction of AGEs with its receptor suppressing the adverse downstream events as $\mathrm{NF}-\kappa \mathrm{B}$ and adhesion molecules. Moreover, cilostazol suppressed renal oxidative stress and regained the anti-oxidative capacity. Thus, Cilostazol therapy attenuated the progression of diabetic nephropathy making it a promising therapeutic target for early diabetic nephropathy. Further clinical studies are required to confirm our results and consider cilostazol a potential therapeutic target to protect against diabetic nephropathy.

\section{Acknowledgment}

The author is deeply grateful to Prof. Kamal El-Qashishy, professor of Pathology, Faculty of Human Medicine, Zagazig University, Egypt for performing the histopathological study.

Conflict of interest: The author declares that there is no conflict of interest.

\section{REFERENCES}

Brosius, F.C., Khoury, C.C., Buller, C.L., Chen, S. 2010. Abnormalities in signaling pathways in diabetic nephropathy. Expert Rev Endocrinol Metab. 5 (1): 51-64. doi:10.1586/eem.09.70

Bucciarelli, L.G., Ananthakrishnan, R., Hwang, Y.C., Kaneko, M., Song, F., Sell, D.R., Strauch, C., Monnier, V.M., Yan, S.F., Schmidt, A.M., Ramasamy, R. 2008. RAGE and modulation of ischemic injury in the diabetic myocardium. Diabetes. 57 (7):1941-51. doi: 10.2337/db07-0326.

D'Agati, V., Schmidt, A.M. 2010. RAGE and the pathogenesis of chronic kidney disease. Nat Rev Nephrol. 6 (6):352-60. doi: 10.1038/nrneph.2010.54.

Daffu, G., Hurtado De Pozo, C., O'Shea, K.M., Ananthakrishnan, R., Ramasamy, R., Schmidt, A.M. 2013. Radical Roles for RAGE in the Pathogenesis of Oxidative Stress in Cardiovascular Diseases and Beyond. Int. J. Mol. Sci. 14 (10): 19891-910. doi: 10.3390/ijms141019891

Dozio, E., Vianello E, Bandera, F., Longhi, E., Brizzola, S., Nebuloni, M., Romanelli, M.M.C. 2019. Soluble Receptor for Advanced Glycation End Products: A Protective Molecule against Intramyocardial Lipid Accumulation 
in Obese Zucker Rats. Mediators Inflamm. Volume 2019, 2712376. doi.org/10.1155/2019/2712376

Feng, Y., Li, C., Liu, Y., Zhang, L., Zhang, Z. 2018. Saxagliptin Attenuates Diabetic Nephropathy with Suppressing Oxidative Stress by Inhibiting AGEs-RAGE Axis in Streptozotocin-Induced Diabetic Rats. American Journal of Internal Medicine. 6 (6): 161-169. doi: 10.11648/j.ajim.20180606.13.

Fishman, S.L., Sonmez, H., Basman, C., Singh, V., Poretsky, L. 2018. The role of advanced glycation endproducts in the development of coronary artery disease in patients with and without diabetes mellitus: a review. Molecular Medicine. 24 (1):59. doi: 10.1186/s10020-018-0060-3.

Fracasso, B.M., Rangel, J.O., Machado, A.G., Curuja, F.S., Lopes, A., Olsen, V., Clausell, N., Biolo, A., Rohde, L.E., Andrades, M. 2019. Characterization of advanced glycation end products and their receptor (RAGE) in an animal model of myocardial infarction. PLoS One. 14 (1): e0209964. doi.org/10.1371/journal. pone.0209964.

Fukami, K., Ueda, S., Yamagishi, S., Kato, S., Inagaki, Y.,Takeuchi, M., Motomiya, Y., Bucala, R., Iida, S., Tamaki, K., Imaizumi, T., Cooper, M.E., Okuda, S. 2004. AGEs activate mesangial TGF-beta-Smad signaling via an angiotensin II type I receptor interaction. Kidney Int. 66 (6): 2137-2147. doi: $10.1111 / j .1523-1755.2004 .66004 . x$

Huang, K., Gao, X., Wei, W. 2017. The Crosstalk between Sirt1 and Keap1/Nrf2/ARE Anti-Oxidative Pathway Forms a Positive Feedback Loop to Inhibit FN and TGF- $\beta 1$ Expressions in Rat Glomerular Mesangial Cells. Exp Cell Res. 361(1): 63-72. doi.org/10.1016/j.yexcr.2017.09.042

Kabil, S.L. 2018. Beneficial effects of cilostazol on liver injury induced by common bile duct ligation in rats: Role of SIRT1 signaling pathway. Clin Exp Pharmacol Physiol. 45 (12):1341-50. doi.org/10.1111/1440-1681.13004

Koike, N., Takamura, T., Kaneko, S. 2007. Induction of reactive oxygen species from isolated rat glomeruli by protein kinase $\mathrm{C}$ activation and TNF- $\alpha$ stimulation, and effects of a phosphodiesterase inhibitor. Life Sciences. 80 (18): 1721-28. doi: 10.1016/j.lfs.2007.02.001.

Lee, E.J., Park, E.Y., Mun, H., Chang, E., Ko, J.Y., Kim, D.Y., Park, J.H. 2015. Soluble receptor for advanced glycation end products inhibits disease progression in autosomal dominant polycystic kidney disease by downregulating cell proliferation. FASEB J. 29 (8): 3506-14. doi.org/10.1096/fj.15272302

Lee, W.C., Chen, H.C., Wang, C.Y., Lin, P.Y., Ou, T.T., Chen, C.C., Wen, M.C., Wang, J., Lee, H.J. 2010. Cilostazol Ameliorates Nephropathy in Type 1 Diabetic Rats Involving Improvement in Oxidative Stress and Regulation of 
TGF- $\beta$ and NF- $\kappa$ B. Biosci Biotechnol Biochem. 74 (7): 1355-61. doi: $10.1271 /$ bbb. 90938

Lindsey, J.B., Cipollone, I.F., Abdullah, S.M., Mcguire, D.K. 2009. Receptor for advanced glycation endproducts (RAGE) and soluble RAGE (sRAGE): cardiovascular implications. Diabetes Vasc Dis Res. 6 (1): 7-14. doi: 10.3132/dvdr.2009.002.

Liu, J.S., Chuang, T.J., Chen, J.H., Lee, C.H., Hsieh, C.H., Lin, T.K., Hsiao, F.C., Hung, Y.J. 2015. Cilostazol attenuates the severity of peripheral arterial occlusive disease in patients with type 2 diabetes: the role of plasma soluble receptor for advanced glycation end-products. Endocrine. 49 (3):703-710. doi: 10.1007/s12020-015-0545-6.

Lu, L., Peng, W.H., Wang, W., Wang, L.J., Chen, Q.J., Shen, W.F.2011. Effects of atorvastatin on progression of diabetic nephropathy and local RAGE and soluble RAGE expressions in rats. J Zhejiang Univ Sci B. 12 (8):652-659. doi: 10.1631/jzus.B1101004.

Lv, X., Yang, L., Tao, K., Liu, Y., Yang, T., Chen, G., Yu, W., Lv, H., Wu, F. 2011. Isoflurane preconditioning at clinically relevant doses induce protective effects of heme oxygenase-1on hepatic ischemia reperfusion in rats. BMC Gastroenterol.11:31. http://www.biomedcentral.com/1471-230X/11/31.

Mestry, S.N., Dhodi, J.B., Kumbhar, S.B., Juvekar, A.R. 2017. Attenuation of diabetic nephropathy in streptozotocin-induced diabetic rats by Punica granatum Linn leaves extract. Journal of Traditional and Complementary Medicine. 7 (3): 273-280. doi: 10.1016/j.jtcme.2016.06.008

Moldogazieva, N.T., Mokhosoev, I.M., Mel'nikova, T.I., Porozov, Y.B., Terentiev, A.A. 2019. Oxidative Stress and Advanced Lipoxidation and Glycation End Products (ALEs and AGEs) in Aging and Age-Related Diseases. Oxid Med Cell Longev. Volume 2019: 3085756. doi.org/10.1155/2019/3085756

Nangaku, M., Miyata, T., Sda, T., Mizuno, M., Inagi, R., Ueda, Y., Ishikawa, N., Yuzawa, H., Kioke, H., Ypersele de Strihou, C.V., Kurokawa, K. 2003. Anti-Hypertensive Agents Inhibit In Vivo the Formation of Advanced Glycation End Products and Improve Renal Damage in a Type 2 Diabetic Nephropathy Rat Model. Am Soc Nephrol. 14 (5): 1212-1222. doi: 10.1097/01.asn.0000062961.76776.c1.

Ni, W., Tang, L., Wei, W. 2015. Research progress in signaling pathway in diabetic nephropathy. Diabetes Metab Res Rev. 31(3): 221-33 doi: 10.1002/dmrr.2568.

Park, S.Y., Lee, S.W., Shin, H.K., Chung, W.T., Lee, W.S., Rhim, B.Y., Hong, K.W., Kim, C.D. 2010. Cilostazol enhances apoptosis of synovial cells from rheumatoid arthritis patients with inhibition of cytokine formation via Nrf2- 
linked heme oxygenase 1 induction. Arthritis Rheum. 62 (3):732-741. doi: 10.1002/art.27291

Quade-Lyssy, P., Kanarek, A.M., Baiersdörfer, M., Postina, R., Kojro, E. 2013. Statins stimulate the production of a soluble form of the receptor for advanced glycation end products. J Lipid Res.54 (11):3052-61. doi: 10.1194/jlr.M038968

Rosario, R.F., Prabhakar, S. 2006. Lipids and diabetic nephropathy. Curr Diab Rep. 6 (6): 455-462. doi: 10.1007/s11892-006-0079-7.

Sanajou, D., Haghjo, A.G., Argani, H., Roshangar, L., Rashtchizadeh, N., Ahmad, S.N.S., Ashrafi-Jigheh, Z., Bahrambeigi, S., Asiaee, F., Rashedi, J., Aslani, S. 2019. Reduction of renal tubular injury with a RAGE inhibitor FPS-ZM1, valsartan and their combination in streptozotocin-induced diabetes in the rat. Eur J Pharmacol. 5 (842): 40-48. doi: 10.1016/j.ejphar.2018.10.035.

Singh, R., Barden, A., Mori, T., Beilin, L. 2001. Advanced glycation end products: a review Diabetologia. 44 (2): 129-46. doi: 10.1007/s001250051591.

Singh, V.P., Bali, A., Singh, N., Jaggi, A.S. 2014. Advanced Glycation End Products and Diabetic Complications. Korean J Physiol Pharmacol. 18 (1):1-14. doi: 10.4196/kjpp.2014.18.1.1.

Sodhi, K., , Puri, N., Favero, G., , Stevens, S., , Meadows, C., Abraham, N.G., , Rezzani, R., Ansinelli, H., , Lebovics, E., Shapiro, J.I. 2015. Fructose Mediated Non-Alcoholic Fatty Liver Is Attenuated by HO-1-SIRT1 Module in Murine Hepatocytes and Mice Fed a High Fructose Diet. PLoS One. 10 (6):e0128648. doi:10.1371/journal.pone.0128648

Su, S.C., Hung, Y.J., Huang, C.L., Shieh, Y.S., Chien, C.Y., Chiang, C.F., Liu, J.S., Lu, C.H., Hsieh, C.H., Lin, C.M., Lee, C.H. 2019. Cilostazol inhibits hyperglucose-induced vascular smooth muscle cell dysfunction by modulating the RAGE/ERK/NF- $\kappa \mathrm{B}$ signaling pathways. Journal of Biomedical Science. 26:68. doi.org/10.1186/s12929-019-0550-9

Takeshita, T., Nakagaw, S., Tatsumi, R., So, G., Hayashia, K., Tanaka, K., Deli, M.A., Nagata, I., Niwa, M. 2014. Cilostazol attenuates ischemia-reperfusioninduced blood-brain barrier dysfunction enhanced by advanced glycation endproducts via transforming growth factor- $\beta 1$ signaling. Molecular and Cellular Neuroscience. 60:1-9. doi: 10.1016/j.mcn.2014.01.006.

Tani, T., Uehara, K., Sudo, T., Marukawa, K., Yasuda, Y., Kimura, Y. 2000. Cilostazol, a Selective Type III Phosphodiesterase Inhibitor, Decreases Triglyceride and Increases HDL Cholesterol Levels by Increasing Lipoprotein Lipase Activity in Rats. Atherosclerosis. 152 (2): 299-305. doi.org/10.1016/S0021-9150 (99)00480-3. 
Thallas-Bonke, V., Thorpe, S.R., Coughlan, M.T., Fukami, K., Yap, F.Y.T., Sourris, K.C., Penfold, S.A., Bach, L.A., Cooper, M.E., Forbe, J.M. 2008. Inhibition of NADPH Oxidase Prevents Advanced Glycation End ProductMediated Damage in Diabetic Nephropathy Through a Protein Kinase C- $\alpha-$ Dependent Pathway. Diabetes. 57 (2): 460-469. doi: 10.2337/db07-1119.

Wang, F., Li, M., Cheng, L., Zhang, T., Hu, J., Cao, M., Zhao, J., Guo, R., Gao, L., Zhang, X. 2008. Intervention with cilostazol attenuates renal inflammation in streptozotocin-induced diabetic rats. Life Sciences. 83 (25-26): 828-835. . doi.org/10.1016/j.lfs.2008.09.027.

Wendt, T.M., Tanji, N., Guo, J., Kislinger, T.R., Qu, W., Lu, Y., Bucciarelli, L.G., Rong, L.L., Moser, B., Markowitz, G.S., Stein, G., Bierhaus, A., Liliensiek, B., Arnold, B., Nawroth, P.P., Stern, D.M., D'Agati, V.D., Schmidt, A.M. 2003. RAGE Drives the Development of Glomerulosclerosis and Implicates Podocyte Activation in the Pathogenesis of Diabetic Nephropathy. Am J Pathol. 162 (4):1123-1137. doi.org/10.1016\%2FS0002-9440 (10)63909-0.

Xu, L., Wang, Y., Li, P., Feng, B. 2016. Advanced glycation end products increase lipids accumulation in macrophages through upregulation of receptor of advanced glycation end products: increasing uptake, esterification and decreasing efflux of cholesterol. Lipids Health Dis. 15:161. doi: 10.1186/s12944-016-0334-0.

Yamagishi, S., Nakamura, K., Imaizumi, T. 2005. Advanced Glycation End Products (AGEs) and Diabetic Vascular Complications. Current Diabetes Reviews. 1(1): 93-106. doi: 10.2174/1573399052952631.

Zhang, S., XU, H., YU, X., WU, Y., SUI, D. 2017. Metformin ameliorates diabetic nephropathy in a rat model of low-dose streptozotocin-induced diabetes. Experimental and Therapeutic Medicine.14 (1): 383-390. doi: 10.3892/etm.2017.4475.

Zhao, X., Zhang, Y., Li, L., Mann, D., Imig, J.D., Emmett, N., Gibbons, G., Jin, L. 2011. Glomerular Expression of Kidney Injury Molecule-1 and Podocytopenia in Diabetic Glomerulopathy. Am J Nephrol. 34: 268-280. doi: $10.1159 / 000330187$.

Ziyadeh, F.N. 2004. Mediators of diabetic renal disease: the case for TGF-Beta as the major mediator, J. Am. Soc. Nephrol. 15: S55-S57. doi: 10.1097/01.ASN.0000093460.24823.5B. 


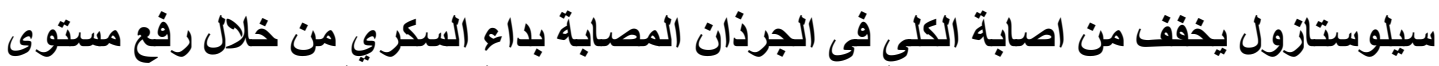

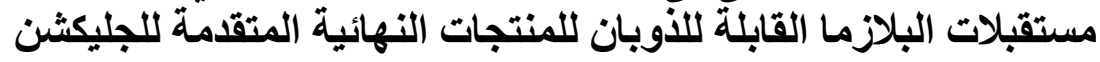

\author{
سعاد لطفى قابيل \\ قسم الفارماكولوجيا الأكلينيكيةـ كلية الطب البشرى- جامعة الزقازيق \\ البريد الاكتروني للباحث الرئيسي : gmail.com
}

(الملخص:

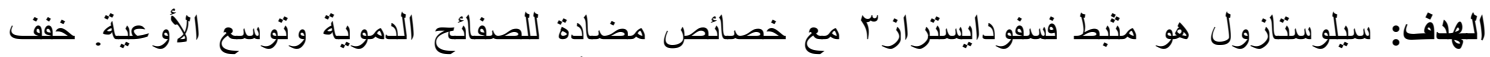

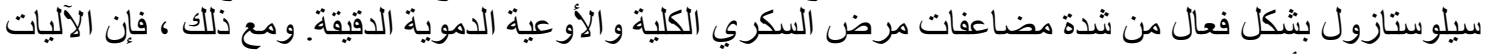
الكامنة وراء تأثثيره المفيد ضدال مند اعتلال الكلية السكري لم يتم توضيحها بالكامل.

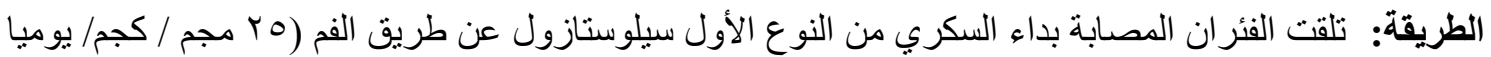

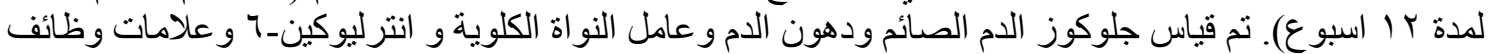

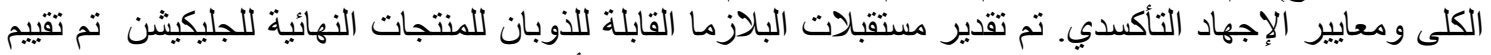

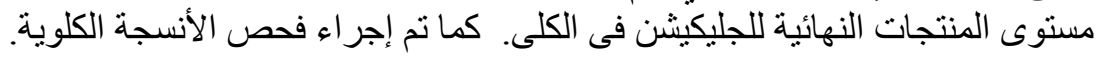

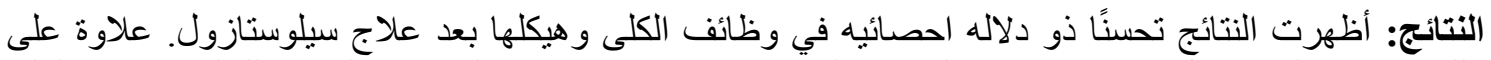

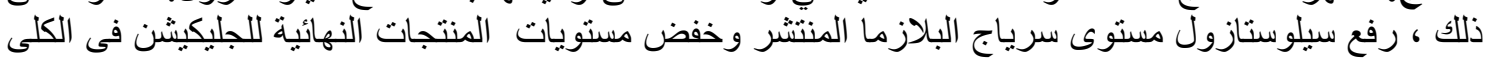

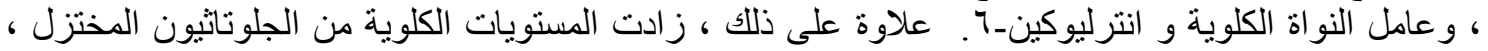

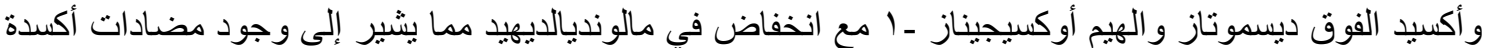
غنية في الكلى.

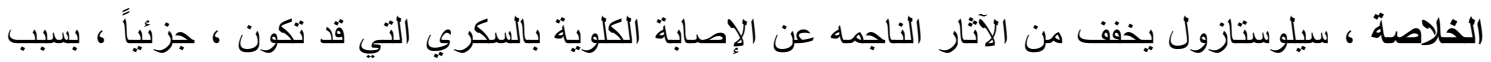

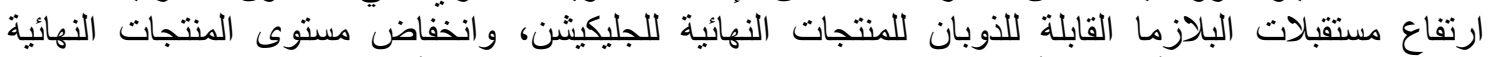

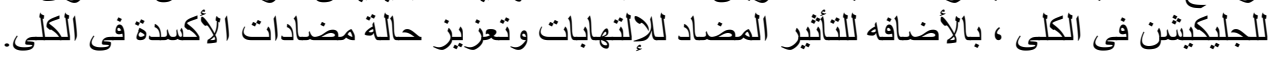

الكلمات الرئيسية: سيلوستازول ، اعتلال الكلية السكري ، الستربتوزونوسين ، مستقبلات قابلة للذوبان للمنتجات النهائية للجليكيشن المتقدمة المئة 